impossible to evert the lid. There was extensive superficial haze of the cornea with punctate deposits on its posterior surface. No view of the iris was obtainable. The patient refused treatment in the hospital and disappeared for ten days. She then returned to hospital with right-sided pneumonia and died in three days.

The right eye was removed for examination. The swelling in the upper conjunctival cul-de-sac had the anatomical. characteristics of a gumma. No tubercle bacilli were found. The ocular conjunctiva was the seat of changes identical with those of the gumma beneath the upper lid, but the cell infiltration was more diffuse and the vascularity less intense. The corneal stroma showed very moderate infiltration, but on the posterior surface there was an extensive and thick cellular deposit. There were other collections of cells free in the exudation filling the aqueous chamber.

The anatomical examination revealed some lesions which could not be observed clinically. In certain localized areas in the ciliary body and in the root of the iris there was cell infiltration identical with that in the ocular conjunctiva, and resulting in much disorganization of these structures. In the rest of their extent the ciliary body and iris showed signs of a moderately severe diffuse inflammation. The other ocular tissues were free from pathological changes. As a result of the anatomical examination, the author calls his case one of "gummatous infiltration of the conjunctiva, the iris and the ciliary body." Nodules of the iris co-existed with a gummatous infiltration of the iris and ciliary body, and with sharply defined gummata, notably the solitary gumma of the conjunctiva. The case was one of untreated syphilis in an old patient; in such instances, as in malignant syphilis, it is not unusual for the delimitation of the various stages of syphilis to be wanting and to find gummata co-existing with lesions of the secondary stage.

J. B. LAWFORD.

\title{
CORRESPONDENCE
}

\section{THE TREATMENT OF MIGRAINE}

\section{To the Editor of the BRITISH JOURNAL OF OPHTHALMOLOGY.}

SIR,-As ophthalmic surgeons are as liable as other mortals to attacks of migraine, I should like some of my fellow sufferers to try the effect of hot fomentations to the back of the head when the attack is beginning, or if the headache stage has already begun, cold or iced applications to the same region. 
It is presumed that the ocular phenomena observed in the early stage of an attack are directly dependent on a wave of contraction of the cortical occipital vessels leading first to an impairment and then to a temporary loss of function of the cortex and therefore to temporary partial blindness.

It is further presumed that the wave of contraction of the vessels is followed by their dilatation allowing excessive blood to the region causing the intense headache and vomiting so usually associated with increased intra-cranial pressure.

The hot fomentations are applied in the hope of inducing the vessels to dilate before the muscle in their walls becomes too starved and fatigued to maintain their normal lumen. If successful in doing this not only will the first stage be cut short, but the second will be prevented.

The cold applications are hoped to cause contraction of the dilated underlying cerebral vessels, either directly or reflexly, or both.

In support of this theory it will be observed that as the vessels, with advancing age, become less elastic, and are therefore by their increasing rigidity less liable to exaggerated variations in their lumen, the attacks become, not only less frequent but also less severe.

A young doctor who suffers severely writes: "I have found the hot fomentations over the cerebellar region of great value, for which advice many thanks."

I should like, Sir, to hear from your readers their personal experience after trial if all other treatment has failed to stop the attack.

Yours faithfully,

WiLliam LANG.

\section{MANUAL OF OPHTHALMIC PRACTICE}

\section{To the Editor of THE BRITISH JOURnAL OF OPHTHALMOLOGy.}

SIR,-In justice to the Indian artists who worked for me, and to Messrs. Thacker, Spink \& Co., who produced the Indian edition of my Manuals of Ophthalmic Practice and Ophthalmic Operations, noticed in your February number, I must ask you to allow me to point out to your readers that the opinion of the plates expressed therein is unfair to them and not met with in other reviews, except that in the British Medical Journal, apparently written by the same hand. In the January number of the American Journal of Ophthalmology, Dr. Edward Jackson, the editor, honours the "Manual of Ophthalmic Practice" by reviewing it himself at some length, and begins by saying "If is somewhat startling to western ophthalmologists to 